\title{
УДК: 621.396
}

\author{
Роман Іванович Грозовський ${ }^{1}$ \\ Наталія Сергї̈вна Бігун ${ }^{2}$
}

\author{
${ }^{1}$ Національний університет оборони Украӥни імені Івана Черняховського, Київ, Украйна \\ ${ }^{2}$ Військова частина А0904, Одеса, Украӥна
}

\section{ОЦІНКА РОЗВІДЗАХИЩЕНОСТІ СИСТЕМИ ЗВ'ЯЗКУ, ПОБУДОВАНОЇ НА СУЧАСНИХ ЗАСОБАХ РАДІОЗВ'ЯЗКУ}

\begin{abstract}
В умовах масового закриття каналів витоку інформації системами криптографічного захисту інформації основним джерелом добування відомостей про характер та стан функціонування елементів системи зв'язку набувають дані радіелектронної розвідки щзодо виявлення, визначення місиезнаходження джерел радіовипромінювання та їхній взаємозв'язок в процесі обміну інформацією. Відомості щүодо виявлення джерел радіовипромінювання та визначення їхнього місцезнаходження забезпечують формування найбільш інформативних структурно-статистичних ознак оперативнотактичної належності об'єктів $і$ джерел розвідки, а викриття взаємозв'язків дозволяє викрити структуру системи радіозв'язку. Для здійснення більш ефективного планування зв'язку та заходів щзодо протидії технічним засобам розвідки обрано підхід щодо очінки розвідзахищеності системи зв'язку $з$ врахуванням показника електромагнітної доступності джерел радіовипромінювання та показника частотно-часового контакту приймача розвідки із складними (хаотичними) сигналами, а саме, сигналами з програмним перелаштуванням робочої частоти та широкосмуговими сигналами.

Ключові слова: сигнали з програмним перелаштуванням робочої частоти; иирокосмугові сигнали; електромагнітна доступність; радіоелектронна розвідка.
\end{abstract}

\section{Вступ}

В сучасних умовах ведення збройної боротьби іiі результат в значній ступені залежить від повноти та своєчасності інформації, необхідної для оцінювання обстановки та прийняття обгрунтованих рішень, а також надійного та скритного управління військами. Центр ваги в протиборстві 3 противником 3 традиційних форм впливу (вогонь, маневр, удар) все більше переноситься в інформаційно-телекомунікаційну область (процес прийняття рішення).

Ефективне управління військами в значній мірі визначається параметрами та характеристиками системи зв'язку збройних сил. Специфічність сучасних систем зв'язку військового призначення полягає в тому, що 3 однієї сторони вони вирішують задачу передачі та обробки даних, а 3 другої сторони - відповідати вимогам щодо стійкості та живучості під час впливу на них противника. За таких умов проблема підвищення розвідзахищеності системи зв'язку піднімається на перший план. При цьому слід передбачати, що досягнення високого рівня розвідзахищеності системи зв'язку залежить від характеристик іiі елементів.

Постановка проблеми. В сучасних системах та комплексах радіо та радіотехнічної розвідки (РРТР) підсистема визначення місцезнаходження функціонально поєднана $з$ підсистемою пошуку. Таким чином, при виявленні сигналу станція РРТР в автоматичному режимі здійснює пеленгацію (засічку) прийнятого сигналу.
Аналіз функціонування системи зв'язку в ході проведення операції Об'єднаних сил та антитерористичної операції показав, що починаючи з моменту ескалації конфлікту на сході України незаконно-створені формування за підтримки сил та засобів Російської Федерації (РФ) постійно здійснювали радіомоніторинг частотного ресурсу, виявлення найбільш інформативних об'єктів, в результаті чого здійснювався вплив на систему зв'язку підрозділів Збройних Сил України як засобами радіоелектронного придушення, так і засобами вогневого ураження [1-3].

Аналіз остатніх досліджень і публікацій. Для оцінювання розвідзахищеності об'єктів військової інфраструктури існують різні методики [4-8], які враховують енергетичні і часові показники, при цьому енергетичні показники характеризуються співвідношенням потужностей сигналів та перешкод на вході приймального пристрою засобів радіоелектронної розвідки, а часові відображають динаміку зміни стану джерел радіовипромінювання. Загальним недоліком методик $\epsilon$ відсутність врахування показника частотно-часового контакту радіосигналів 3 програмним перелаштуванням робочої частоти (ППРЧ) та показника електромагнітної доступності для широкосмугових сигналів передавання, що впливає на ймовірність виявлення джерел радіовипромінювання та точність визначення місцезнаходження радіотехнічних систем зі складними сигналами. 
Метою статті $\epsilon$ проведення оцінки розвідзихещеності системи зв'язку, організованої на сучасних цифрових засобах радіозв'язку.

Виклад основного матеріалу дослідження.

Одним 3 основних показників розвідзахищеності системи зв'язку є ймовірність виявлення елементів системи зв'язку. Цей показник залежить від ряду чинників.

До основних зовнішніх чинників, які впливають на виявлення функціонування радіотехнічних засобів слід віднести: кількість постів пошуку, час перегляду діапазону частот приймачем розвідки 3 технічною швидкістю аналізу, чутливість приймача розвідки (порогове значення співвідношення сигнал/шум). До основних внутрішніх чинників слід віднести: швидкість передачі інформаційного повідомлення, діапазон частот передавання широкосмугових сигналів (база сигналу) та потужність передавача. Вищезазначені чинники суттєво впливають на ймовірність частотно-часового контакту сигналу та ймовірність електромагнітної доступності сигналів $з$ приймачем розвідки.

Поряд 3 основними показниками (ймовірність частотно-часового контакту та ймовірність енергетичного контакту) на виявлення об'єктів розвідки суттєво впливає показник електромагнітної доступності радіотехнічних засобів зі складними сигналами, які характеризуються збільшеною шириною спектру передавання [9-10].

Для широкосмугових сигналів база сигналу співпадає 3 шириною спектру шуму, в результаті чого співвідношення сигнал шум буде набагато менше одиниці.

Таким чином, ймовірність електромагнітної доступності джерел радіовипромінювання 3 широкосмуговими сигналами залежить від бази сигналу та співвідношення сигнал/шум на вході приймача розвідки, який розраховується згідно виразу

$$
p_{\text {емд }}=F\left(\frac{P_{\text {пер }}}{B V_{\text {гіп }} G_{\text {шा }}} / h_{\text {пр }}^{2}\right),
$$

де: $P_{\text {емд }}-$ ймовірність

електромагнітної доступності;

$B$ - база сигналу;

$P_{\text {пер }}-$ потужність передавача;

$V_{\text {iп }}$ - швидкість передачі інформаційного повідомлення;

$h_{\text {пр }}^{2}-$ співвідношення сигнал/шум на вході приймача розвідки;

$G_{\text {ш }}$ - спектральна щільність потужності шуму.

Проведені розрахунки показали (рис. 1), що зі збільшення бази сигналу більше ніж 1 МГц ймовірність електромагнітної доступності джерел радіовипромінювання буде задовольняти встановленим вимогам. При цьому, безкінечне розширення бази сигнали не має доцільності, так як зі збільшенням бази сигналу більше 3 МГц рівень електромагнітної доступності залишається незмінним.

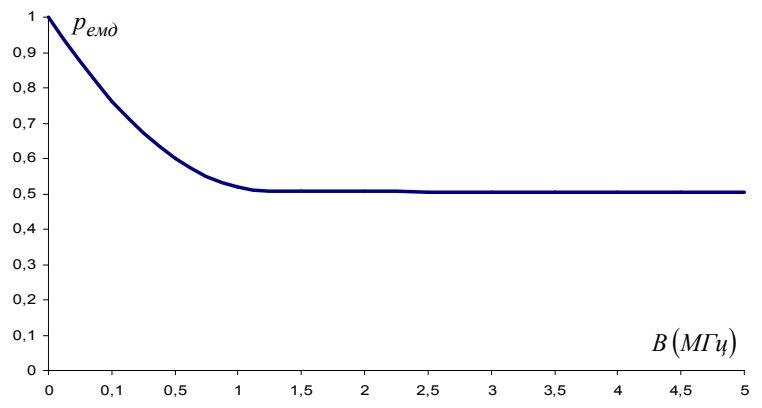

Рис. 1. Графік залежності ймовірності електромагнітної доступності від бази сигналу

Поряд 3 цим, для адекватного оцінювання розвідзахищеності мереж радіодоступу з штучним розширенням спектру передавання повинні бути прийняті до уваги наступні оперативно-технічні особливості їх функціонування, а саме:

радіостанції, які працюють в режимі радіодоступу мають випадковий трафік випромінювання коротких пакетів з інтенсивністю від 0,1 до 1 пакету за вікно в режимі випадкового багатостанційного доступу;

для передачі даних використовуються сигнали зі швидкістю передавання до 50 Кбіт/с;

маршрутизація пакетів визначається радіодоступністю станції, а також завантаженням транзитних (ретрансляційних) станцій.

Таким чином, для оцінювання розвідзахищеності системи зв'язку необхідно враховувати швидкість передачі інформації, що впливає на електромагнітну доступність джерел радіовипромінювання.

Проведені розрахунки показали, що при базі сигналу 3 МГц зі збільшенням передачі інформації електромагнітна доступність джерел радіовипромінювання різко знижується, та на швидкості більше 4,8 Кбіт/с вирівнюється на рівні 0,5 (рис. 2). Подальше збільшення швидкості передавання впливає лише на пропускну здатність системи зв'язку.

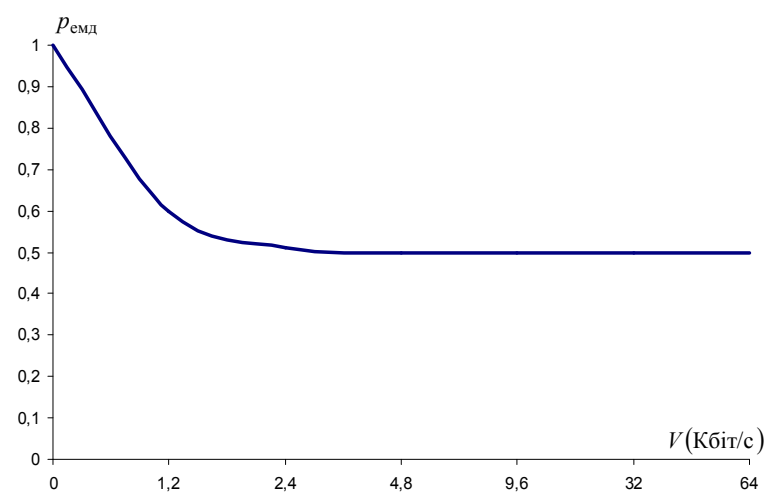

Рис. 2. Графік залежності ймовірності електромагнітної доступності від швидкості передавання даних 
Узагальнений показник щодо виявлення функціонування джерел радіовипромінювання характеризує виконання трьох сумісних подій, а саме: енергетичного виявлення сигналів, енергетичного контакту сигналів 3 приймачем розвідки, електромагнітної доступності джерел радіовипромінювання при організації мереж радіодоступу. Таким чином, для розрахунку ймовірності виявлення функціонування джерел радіовипромінювання використовуємо вираз:

$$
p_{\text {вияв }}=p_{\text {ччк }} p_{\text {ек }} p_{\text {емд }},
$$

де: $P_{\text {вияв }}-$ ймовірність виявлення функціонування джерела радіовипромінювання;

$P_{\text {ччк }}-$ ймовірність частотно-часового контакту;

$P_{\text {ек }}-$ ймовірність енергетичного контакту.

На практиці прийнято вважати, що мета по скритному функціонуванню мережі радіозв'язку вважається досягнута, якщо виявлено менше $80 \%$ іiї елементів. Таким чином, ймовірність виявлення має буди меншою $0,8\left(p_{\text {вияв }}<0,8\right)$.

Проведені розрахунки показали (рис. 3), що при швидкості передачі інформації 1,2 Кбіт/с, потужності передавача 100Bт, ймовірності енергетичного виявлення $0,8 \quad\left(p_{\text {ев }}=0,8\right)$, ймовірності частотно-часового контакту 0,6 $\left(p_{\text {ччк }}^{\text {рл }}=0,6\right)$ зі зростанням бази сигналу більше $1 \mathrm{MГц} \mathrm{забезпечується} \mathrm{необхідний} \mathrm{рівень} \mathrm{скритного}$ функціонування мережі радіодоступу.

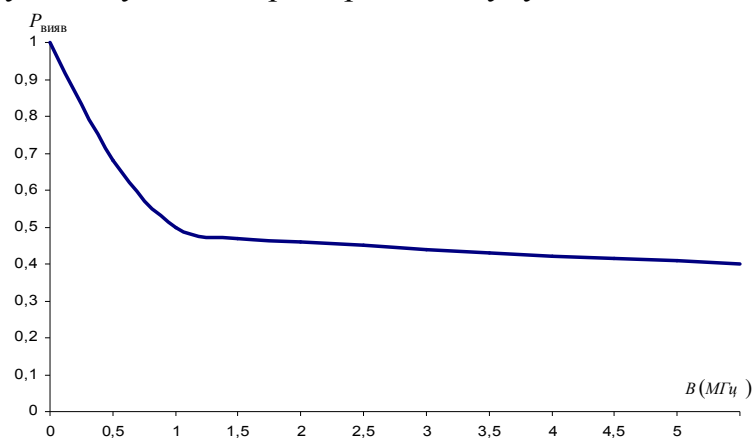

Рис. 3. Графік залежності ймовірності виявлення функціонування джерел радіовипромінювання від бази сигналу

Поряд 3 цим, при оцінюванні розвідзахищеності системи зв'язку необхідно враховувати показник точності визначення місцезнаходження елементів, який характеризується ймовірністю визначення місцезнаходження джерел радіовипромінювання системи зв'язку з заданою точністю визначення координат джерел радіовипромінювання.

У даному випадку запропоновано та впроваджено залежність швидкості перелаштування (скачків) по частоті сигналу передавання до технічної швидкості пеленгації станцій радіо та радіотехнічної розвідки противника [3], що в свою чергу впливає на ймовірність частотно-часового контакту сигналу 3 програмним перелаштуванням робочої частоти 3 пеленгаторним постом:

$$
p_{\text {ччк } i}^{\text {ппрч }}=\exp \left(-\frac{V_{\text {пер }}^{\text {ппрч }}}{2 V_{\text {резв }}^{\text {пел }}}\right),
$$

де: $V_{\text {nер }}^{\text {прч }}-$ швидкість перелаштування передавача по частоті;

$V_{\text {розв }}^{\text {пел }}-$ швидкість панорамного огляду діапазону частот розвідки.

При цьому необхідно враховувати можливості системи радіоелектронної розвідки щодо точності визначення місцезнаходження джерел радіовипромінювання (рис. 4), яка виражається лінійним радіусом виявлення $\left(R_{\text {ск }}\right)$ та характеризує відстань між дійсним розташуванням джерела випромінювання до точки ймовірного його місцезнаходження:

$$
R_{\mathrm{c \kappa}}=0,01745 \sqrt{\frac{\sum_{k=1}^{n} \frac{1}{L_{k}}}{\sum_{i=1}^{n-1} \sum_{k=i+1}^{n} \frac{\sin \gamma_{i k}}{L_{i} L_{k}}}},
$$

де: $L_{k}, L_{i}-$ віддаль лінії пеленгу і-го пеленгатора від місцезнаходження ДРВ;

$\gamma_{i k}-$ кут пересічення $\mathrm{i}-\ddot{i}$ та $\mathrm{k}-\ddot{\mathrm{i}}$ лінії місцезнаходження.

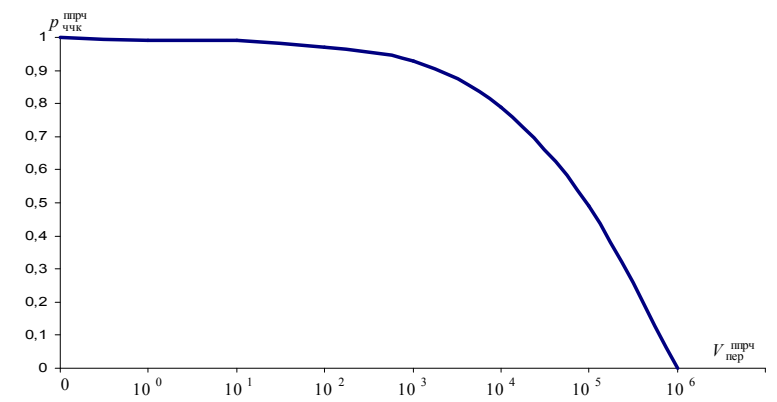

Рис.4. Графік залежності ймовірності частотно-часового контакту сигналу від швидкості перелаштування

Як видно з графіку (рис. 4), при збільшенні швидкості скачків сигналу 3 програмним перелаштуванням робочої частоти ймовірність частотно-часового контакту зменшується, а при досягненні технічної швидкості пеленгації (швидкості перегляду діапазону частот розвідки) зводиться до 0. Таким чином, при надшвидкому (побітовому) перелаштуванні частоти визначити місцезнаходження джерела радіовипромінювання неможливе.

У відповідності до закономірностей розповсюдження радіохвиль у вільному просторі при збільшенні швидкості перелаштування зменшується дальність зв'язку за рахунок зменшення часу синхронізації джерел радіовипромінювання та часу отримання квитанції щодо підтвердження достовірності передачі інформаційного повідомлення.

Поряд 3 цим, необхідно враховувати 
електромагнітну доступність джерел радіовипромінювання 3 сигналами програмного перелаштування робочої частоти з пеленгаторною станцією. Так як передавання сигналів 3 програмним перелаштуванням робочої частоти здійснюється в широкому спектрі частот, використовуємо для розрахунку електромагнітної доступності вираз (1).

Точність визначення місцезнаходження джерел радіовипромінювання в значній мірі залежить від технічних характеристик пеленгаторної станції, а саме, середнього значення радіусу середньоквадратичної похибки визначення місцезнаходження, що впливає на лінійне значення радіусу пошуку $\left(R_{\text {ск }}\right)$ пеленгаторної мережі, яка складається 3 певної кількості станцій радіоелектронної розвідки. Отже, при оцінюванні визначення місцезнаходження джерел радіовипромінювання необхідно знати структуру підсистеми визначення місцезнаходження.

Ймовірність визначення місцезнаходження для різної кількості пеленгаторних постів, які здійснюють пеленгацію у визначеному секторі розвідки розраховуємо згідно виразу:

$$
p_{\text {мз }}=p_{\text {пел }}=1-\left\{\left(1-p_{\text {пел }}^{1}\right)^{n}\left[1+n\left(\frac{p_{\text {пел }}^{1}}{1-p_{\text {пел }}^{1}}\right)\right]\right\},
$$

де: $p_{\text {пел }}^{1}-$ ймовірність зняття пеленгу одним постом;

$n$ - кількість пеленгаторів, які приймають участь в пеленгації;

$p_{\text {пел }}-$ ймовірність зняття пеленгу мережею.

Отримані результати показали (рис. 5), що при збільшенні швидкості перелаштування сигналів 3 ППРЧ достовірність визначення місцезнаходження джерел радіовипромінювання системи зв'язку при незначній кількості пеленгаторних постів буде задовольняти встановленим вимогам щодо скритного функціонування елементів системи зв'язку.

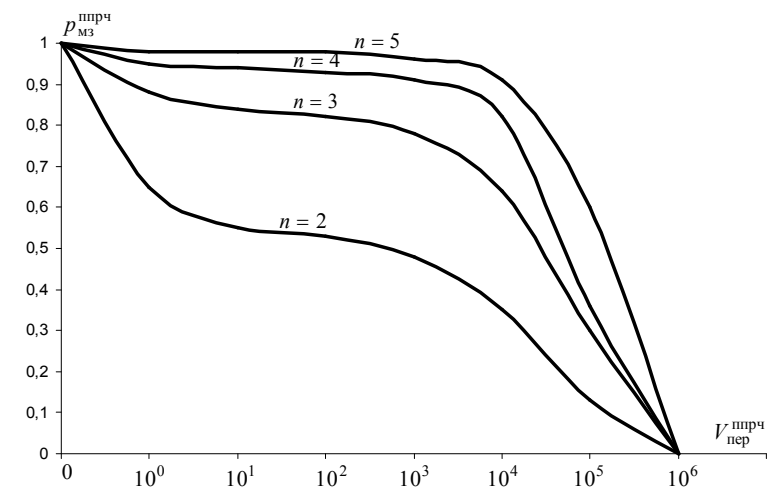

Рис. 5. Залежність ймовірності визначення місцезнаходження джерел радіовипромінювання від ППРЧ

При оцінюванні визначення місцезнаходження джерел радіовипромінювання враховується база сигналу з ППРЧ.
Як показали розрахунки, при швидкості ППРЧ 1000 скачків в секунду $\left(V_{\text {пер }}^{\text {ппр }}=10^{3}\right)$ та складу пеленгаторної мережі в секторі ведення розвідки 3 трьох пеленгаторних постів $(n=3)$ зі збільшенням бази сигналу більше 1 МГц забезпечується необхідний рівень скритного функціонування джерел радіовипромінювання системи зв'язку.

Проведені розрахунки показали (рис. 6), що при виборі режиму роботи засобів зв'язку широкосмугового доступу з базою сигналу більше 1,5 МГц забезпечує необхідний рівень розвідзахищеності системи зв'язку навіть при значній кількості постів пошуку (виявлення) системи РРТР, що в свою чергу дає можливість розробити рекомендації щодо умов функціонування засобів зв'язку та вибору режимів їхньої роботи при організації зв'язку.

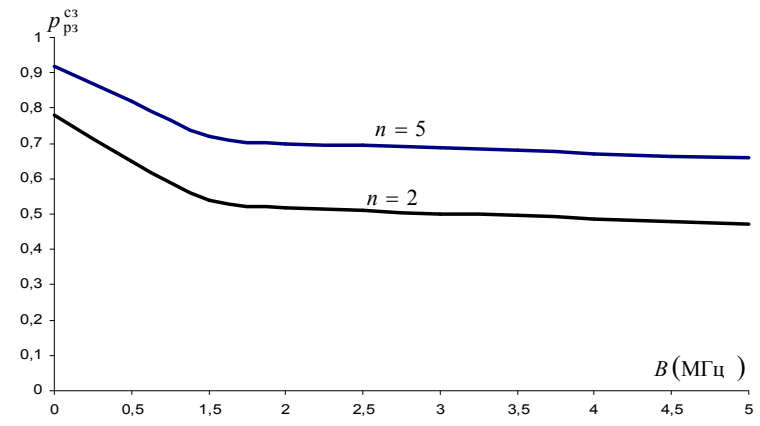

Рис.6. Залежність розвідзахищеності від бази сигналу при організації мереж доступу

Однак, при оцінюванні розвідзахищеності системи зв'язку необхідно також враховувати функціонування радіозасобів системи зв'язку із режимом роботи програмного перелаштування робочої частоти, що в свою чергу впливає на визначення місцезнаходження джерел радіовипромінювання.

Як видно з графіків (рис. 7), при швидкості програмного перелаштування робочої частоти більше 10000 скачків за секунду з базою сигналу 2 МГц забезпечується необхідний рівень розвідзахищеності за умови пеленгації двома постами визначення місцезнаходження. За таких самих умов, але при здійсненні пеленгації п'ятьма постами необхідний рівень розвідзахищеності забезпечується при збільшенні швидкості до 100000 скачків в секунду.

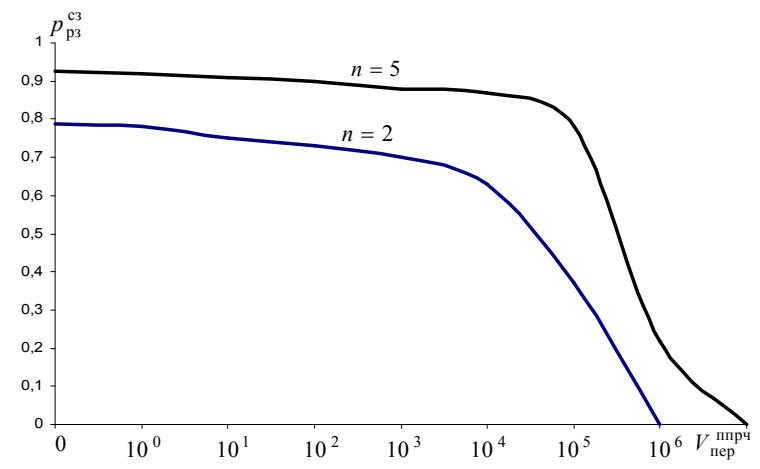

Рис. 7. Графік залежності розвідзахищеності системи зв'язку від швидкості роботи ППРЧ 
У зв'язку з тим, що основою розвідувальних даних $\epsilon$ повітряна розвідка, а час ii функціонування $є$ обмеженим, при оцінюванні необхідно враховувати час ведення розвідки, який буде впливати на розвідзахищеність системи зв'язку:

$$
p_{\text {рз }}^{\text {С3 }}\left(t_{\text {викр }} \geq T_{\text {доп }}\right)=1-\exp \left(-\lambda_{\text {рер }} T_{\text {р }}\right),
$$

де $T_{\mathrm{p}}$ - час ведення радіоелектронної розвідки.

На рис. 8 зображено графіки залежності розвідзахищеності системи зв'язку від часу ведення радіоелектронної розвідки при функціонуванні засобів зв'язку в різних режимах роботи.

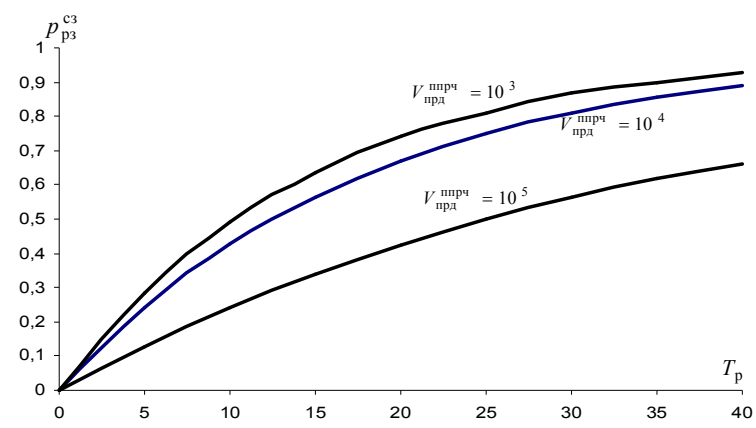

Рис.10. Графік залежності розвідзахищеності системи зв'язку при різних значеннях швидкості роботи ППРЧ

\section{Jimepamypa}

1. Гусаров В. Особливості організації і ведення радіоелектронної боротьби в боях за Іловайськ. [Електронний ресурс]. - режим доступу: http://sprotyv.info. 2. Гусаров В. Тактика російських груп РЕБ в боях за Дебальцево. Аналітика "IC". [Електронний ресурс]. - режим доступу: http://sprotyv.info. 3. Радіоелектронна боротьба російських терористичних сил на початковій фазі військового конфлікту в Україні. [Електронний ресурс]. - режим доступу: http://sprotyv.info. 4. Боговик В.В. Эффективность систем военной связи и методы ее оценки - СПб.: ВАС, 2006. - 182 с 5. Борисов В. И. Помехозащищенность систем радиосвязи с расширением спектра сигналов методом псевдослучайной перестройки рабочей частоты - М.: Радио и связь, 2000. - 384 с. 6. Литвиненко В.П. Энергетическая скрытность сигналов и защита радиолиний: учеб. пособие. Воронеж: ГОУВПО "Воронежский государственный технический
Отримані результати показали, що при швидкості ППРЧ 1000 скачків у секунду з вибором ширини спектру передавання 1МГц забезпечується розвідзахищеність функціонуючої системи зв'язку до 30 годин безперервного функціонування системи радіо та радіотехнічної розвідки (рисунок 10, 11), яка складається 3 трьох постів радіоелектронної розвідки та оцінки електромагнітної обстановки.

\section{Висновки й перспективи подальших досліджень}

Таким чином, в тактичній ланці управління використовувати УКХ радіостанції 3 широкосмуговими сигналами із базою сигналу більше 1 МГц та використовувати режим роботи швидкої та надшвидкої ППРЧ 3 частковим перекриття спектру передавання що забезпечить скритне функціонування системи зв'язку до 20 годин без зміни ії топології.

Отримані результати можуть бути використані в практиці при плануванні та розгортанні системи зв'язку, плануванні заходів щодо протидії технічним засобам розвідки, у навчальному процесі у вищих військових навчальних закладах та під час проведення подальших досліджень за даним напрямом университет", 2009. - 166 с. 7. Макаренко С.И., Иванов М.С., Попов С.А. Помехозащищенность систем связи с псевдослучайной перестройкой рабочей частоты. Монография. - СПб.: Свое издательство, 2013. 166 с. 8. Помехозащищенность радиосистем со сложными сигналами - М. : Радио и связь, 1985. - 264 c.31. 9. Грозовський P.I. "Удосконалена часткова методика розрахунку ймовірності визначення місцезнаходження джерел радіовипромінювання системи зв'язку оперативно-тактичного угруповання військ (сил) в стабілізаційній операціі” // Збірник наукових праць НУОУ ім. І.Черняховського, 2017. - №2 (141). 10. Грозовський Р.I. "Удосконалена часткова методика розрахунку ймовірності виявлення об'єктів радіо і радіотехнічної розвідки оперативно-тактичного угруповання військ (сил) в стабілізаційній операції” // Збірник наукових праць НУОУ ім. І.Черняховського, 2017. - №1 (140).

\title{
ОЦЕНКА РАЗВЕДЗАЩИЩЕННОСТИ СИСТЕМЫ СВЯЗИ, ПОСТРОЕННОЙ НА СОВРЕМЕННЫХ СРЕДСТВАХ РАДИОСВЯЗИ
}

\author{
${ }^{1}$ Роман Иванович Грозовский \\ ${ }^{2}$ Наталья Сергеевна Бигун
}

\section{${ }^{1}$ Национальный университет обороны Украины имени Ивана Черняховского, Киев, Украина ${ }^{2}$ Воинская часть А0904, Одесса, Украина}

В условиях массового закрытия каналов утечки информации системами криптографической защить информации основным источником добывания сведений о характере и состоянии функиионирования элементов системы связи приобретают данные радиоэлектронной разведки по выявлению, определения местоположения источников радиоизлучения и их взаимосвязь в процессе 
обмена информачией. Сведения по выявлению источников радиоизлучения и определение их местоположения обеспечивают формирование наиболее информативных структурно-статистических признаков оперативно-тактической принадлежности объектов и источников разведки, а вскрытие взаимосвязей позволяет вскрыть структуру системы радиосвязи. Для осуществления более эффективного планирования связи и мероприятий по противодействию техническим средствам разведки избран подход к оченке разведывательной защищенности системы связи с учетом показателя электромагнитной доступности источников радиоизлучения и показателя частотно-временного контакта приемника разведки со сложными (хаотическими) сигналами, а именно, сигналами с программной перестройкой рабочей частоты и широкополосными сигналами.

Ключевые слова: сигналь с программной перестройкой рабочей частоть; иирокополоснье сигналь; электромагнитная доступность; радиоэлектронная разведка.

\title{
ESTIMATION OF THE EDUCATIONAL SECURITY OF THE COMMUNICATION SYSTEM BUILT ON THE MODERN RADIO COMMUNICATION MEANS
}

\author{
${ }^{1}$ Roman Hrozovskyi \\ ${ }^{2}$ Nataliia Bihun \\ ${ }^{1}$ National Defence University of Ukraine named after Ivan Cherniakhovsky, Kyiv, Ukraine \\ ${ }^{2}$ Military unit A0904, Odessa, Ukraine
}

In the conditions of mass closure of information leakage channels, cryptographic information protection systems acquire the electronic intelligence data for identifying, locating radio sources and their interconnection in the process of information exchange by the main source for obtaining information about the nature and state of functioning of the communication system elements. Information on identifying sources of radio emission and determining their location provides for the formation of the most informative structural and statistical signs of operational and tactical affiliation of objects and sources of intelligence, and the opening of interconnections allows revealing the structure of a radio communication system. For more effective planning of communications and measures to counter reconnaissance equipment, an approach was chosen to assess the reconnaissance security of the communications system, taking into account the electromagnetic availability indicator of radio sources and the indicator of time-frequency contact of the reconnaissance receiver with complex (chaotic) signals, namely, program-controlled signals operating frequency and wideband signals.

Keywords: signals with software restructuring of the operating frequency; broadband signals; electromagnetic accessibility; electronic intelligence.

\section{References}

1. Gusarov V. Features of the organization and conduct of electronic warfare in the battle for Ilovajsk. [Electronic resource]. - access mode: http://sprotyv.info. 2. Gusarov V. Tactics of Russian groups of REB in the battles for Debaltsevo. Analyst "IC". [Electronic resource]. - access mode: http://sprotyv.info. 3. Radio electron struggle of Russian terrorist forces in the initial phase of the military conflict in Ukraine. [Electronic resource]. - access mode: http://sprotyv.info. 4. Bogovik V.V. Efficiency of military communication systems and methods of its estimation $-\mathrm{SPb}$ $\therefore$ VAS, 2006. - 182 p. 5. Borisov V. I. Interference immunity of radio communication systems with the expansion of the spectrum of signals by the method of pseudorandom adjustment of the working frequency Moscow: Radio and Communications, 2000. - 384 with. 6. Litvinenko V.P. Energy concealment of signals and protection of radio links: study. allowance Voronezh: GOUVPO "Voronezh State Technical University", 2009 166 p. 7. Makarenko S.I., Ivanov MS, Popov S.A.
Interference immunity of communication systems with pseudorandom processing of the working frequency. Monograph - SPb .: Its publishing house, 2013. - $166 \mathrm{pp}$. 8. Interference immunity of radio systems with complex signals, ed. G.I. Tuzov. - Moscow: Radio and Communications, 1985. - 264 p.31. 9. Hrozovskyi R.I. "Improved partial method for calculating the probability of determining the location of sources of radio emission of the system of communication of the operational-tactical grouping of troops (forces) in the stabilization operation" // Collection of scientific works of the National Academy of Sciences of Ukraine. I. Chernyakhovsky, 2017. - No. 2 (141). 10. Hrozovskyi R.I. "Improved partial methodology for calculating the probability of detecting radio and radiointelligence objects of the operational-tactical grouping of troops (forces) in a stabilization operation" / / Collection of scientific works of NIOU them. I. Chernyakhovsky, 2017. №1 (140). 